\title{
Good Clinical Practice - Need of the Hour
}

The sixth most common disease in the world - periodontitis, causes tooth loss. Illiteracy and low socio-economic status have been attributed as a cause for the neglected periodontal status. Not many studies are available on the prevalence of the periodontal disease in Nepal. The two hospital-based studies on the prevalence of periodontal disease in Nepal observe that periodontal disease is the main cause of extraction of tooth in the 51-60 years age group, and 55.6\% of extraction in the 30 years and above age group was due to periodontal disease. ${ }^{1}$

Patients in general dental practice present with a wide range of periodontal problems. The eventual tooth loss affects the mastication, phonation, esthetics and the quality of life. Periodontal care has to be the main area of focus in general dental practice as other dental treatment may fail if the periodontal disease is not controlled. ${ }^{2}$

General dental practitioners may have a very limited interest in treating periodontal problems as their knowledge and attitude is limited to the level that was achieved during graduation. The general dental practitioners should be educated on the importance of the periodontal examination and also the referral to the periodontist for treatment of conditions which are beyond their scope and skill. ${ }^{3}$

An important point concluded from the study amongst the general dental practitioners of London in terms of training and its evaluation and also expectation and outcomes for health professionals is the improvement in the periodontal health education and the skill development; ultimately resulting in the benefit to the patient. The general dental practitioner ended up with enhanced appreciation of inter-professional working which contributed to their professional status and development. ${ }^{4}$

\footnotetext{
Correspondence:

Dr. Balaji Manohar, Principal, Prof and Head,

Department of Periodontology,

Kalinga Institute of Dental Sciences,

KIIT Deemed to be University,

Bhubaneswar, Odisha, India.

email:drbalajimanohar@gmail.com

Citation

Manohar B. Good Clinical Practice - Need of the Hour. J Nepal Soc Perio Oral Implantol. 2020;4(7):3-4.

DOI: https://doi.org/10.3126/jnspoi.v4i1.30894
}

The Nepalese Society of Periodontology and Oral Implantology, a premier organization promoting the art and science of periodontology needs to lead from the front in setting up guidelines for general dentists and other dental specialists to manage the periodontal patient who come for treatment to them in the best possible way by providing quality treatment which can in no way exclude treating the periodontal condition. The society is already conducting conferences, clinical meetings and postgraduate conventions. ${ }^{5}$

The society can take step and formulate clinical guidelines as have been formulated. The Good Practitioner's Guide to Periodontology ${ }^{6}$ by British Society of Periodontology, Prevention and Treatment of Periodontal Diseases in Primary Care $^{7}$ by Scottish Dental Clinical Effectiveness Programme, JSP Clinical practice guideline ${ }^{8}$ by Japanese Society of Periodontology and the Guidelines on periodontal care ${ }^{9}$ by the Indian Society of Periodontology, to cite a few. The guidelines should be framed after discussions with a panel of experts that may include general dental practitioners, Periodontist, academicians from other dental specialty organizations, mainly Prosthodontist, Endodontist and Aesthetic Dentist, Orthodontist, Oral Stomatologist as well as Endocrinologist, Gynecologist and Neurologist.

The guidelines should be a comprehensive collection of data with respect to the health and disease of the periodontal tissue, etiology of the periodontal disease, pathology, classification, the screening and charting of periodontal findings, diagnosis and treatment. The guideline should also include the basic instrumentation to treat the periodontal disease in their own dental clinic and to also believe in referral of patient that is beyond their scope of treatment which might include surgical intervention for the benefit of the patient. ${ }^{9}$

An initiative by NSPOI at a stage, when the dental practitioner population is just about increasing in the country but still is within the reach, will create awareness about the periodontal disease and its treatment which in turn will provide quality treatment to the Nepalese population at the right time in their own town and not make the patient come to a tertiary centre like at the capital Kathmandu when the clinical condition is too late. 


\section{REFERENCES}

1. Manohar B, Humagain M. Periodontal disease-is prevention possible? Kathmandu Univ Med J. 2018;16(64):275-6.

2. Periodontal screening and management: the foundation of general dental practice. In Bartold, PM and Chung, KM (Eds.), Periodontics: beyond the pocket: hosted by Asian Pacific Society of Periodontology, 29-30 August 2009, Singapore, p. 58-65. Adelaide: Asian Pacific Society of Periodontology, 2010.

3. Cherian DA, Dayakar MM, Thermadam TP. Rationale of referral of patients to a periodontist by general practitioners: Review with a cross-sectional survey. J Interdiscip Dentistry. 2015 Jan 1;5(1):7.

4. Ghotane SG, Harrison V, Radcliffe E, Jones E, Gallagher JE. Enhanced skills in periodontology: evaluation of a pilot scheme for general dental practitioners and dental care professionals in London. Br Dent J. 2017 May;222(9):700-7.

5. Pradhan S, Koirala PK. Periodontics in Nepal: where have we reached? J Nepal Soc Perio Oral Implantol. 2019;3:38-9.

6. Needleman I. The Good Practitioner's Guide to Periodontology. Br Soc Periodontol. 2016.

7. Dental S. Prevention and Treatment of Periodontal Diseases in Primary Care Dental Clinical Guidance. Scottish Dental Clinical Effectiveness Programme. 2014 Jun.

8. JSP clinical practice guideline. Japanese Society of Periodontology. 2015. Available at: http://www.perio.jp/publication/upload_file/ guideline_perio_plan2015_en.pdf

9. $\quad$ Kumar A. Clinical Good Practice Guidelines (CGPR): A step in right direction. J Indian Soc Periodontol. 2019 Mar;23(2):89. 